\title{
Para além do fonológico: uma live ousada, política e esperançosa
}

\author{
Marcelo Fernandes de ARAUJO (D) \\ Universidade Federal de Pernambuco (UFPE) \\ Siane Gois Cavalcanti RODRIGUES (1) \\ Universidade Federal de Pernambuco (UFPE)
}

RESUMO

OPEN ACCESS

EDITADO POR

Raquel Freitag

AVALIADO POR

Thaïs Cristófaro Silva

SOBRE OS AUTORES

Marcelo Fernandes de Araujo Contribuiu com Siane Gois

Cavalcanti Rodrigues. Papéis: escrita - rascunho original.

Siane Gois Cavalcanti Rodrigues

Contribuiu com Marcelo

Fernandes de Araujo. Papéis:

escrita - análise e edição.

DATAS

Recebido: 23/07/2020 Aceito: 01/09/2020 Publicado: 08/09/2020

COMO CITAR Araujo, M. F.; Rodrigues. S. G. C. (2020). Para além do fonológico: uma live ousada, política e esperançosa. Revista da Abralin,

v. 19, n. 2, p. 1-4, 2020.
Esta é uma resenha da conferência Fonologia: conquistas e desafios, proferida, no Abralin ao Vivo - Linguistics on-line, por Thaïs Cristófaro Silva, cuja fala foi marcada por seu posicionamento crítico acerca da atual conjuntura política do Brasil e do papel da comunidade científica no desenvolvimento de mecanismos voltados ao combate às desigualdades sociais. Ela destacou a interação entre a Fonética e a Fonologia e chamou a atenção para os três principais avanços da Fonética: o IPA, os avanços experimentais com diferentes tecnologias e a hipótese da motricidade cognitiva. Quanto à Fonologia, Cristófaro Silva (2020) abordou os seguintes fenômenos fonológicos do Português Brasileiro: a nasalização de vogais, a palatalização das oclusivas alveolares e o apagamento do [i] átono. Por fim, reconheceu os desafios a serem enfrentados pelas áreas em pauta, como integrar as diversas ciências cognitivas, elaborar novas terminologias, ampliar o conhecimento sobre o Português Brasileiro, valorizar o plurilinguismo e socializar o conhecimento.

\section{ABSTRACT}

This is a review of the conference Fonologia: conquistas e desafios, aired live at Abralin (Brazilian Linguistic Association) and delivered by Thais Cristófaro Silva, whose discourse has been highlighted by a critical placement regarding the current political situation in Brazil and by the scientific community role on the development of mechanisms aimed at combating social inequality. She emphasized the interaction between 


\section{REVISTA DA ABRALIN}

Phonetics and Phonology by bringing out three main advances on Phonetics: the IPA, the empirical advances on different technologies and the cognitive motricity hypothesis. Concerning Phonology, Cristófaro Silva (2020) pointed out the Brazilian Portuguese phonological phenomena, as follows: vowel nasalization, palatalization of alveolar stops and erasure of the unstressed [i]. Lastly, she recognized the challenges to be faced by areas in question, such as the integralization of several cognitive sciences, the elaboration of new terminologies, the valorization of plurilingualism and the socialization of knowledge.

\section{PALAVRAS-CHAVE}

Fonética. Fonologia. Avanços Científicos.

\section{KEYWORDS}

Phonetics. Phonology. Scientific advances.

Thaïs Cristófaro Silva (UFMG/CNPq/FAPEMIG) iniciou a sua fala apresentando o seu posicionamento crítico acerca da atual conjuntura política do Brasil e do papel da comunidade científica no desenvolvimento de mecanismos voltados ao combate às desigualdades sociais. A seguir, advertiu que a sua fala seria voltada para os estudantes e que o seu objetivo não era trazer verdades, mas sim ideias.

Ao abordar o que já está posto nos campos da Fonética e da Fonologia, a fonóloga advogou a favor de novas formas de análise. Décadas após o lançamento do conhecido livro Fonética e Fonologia do Português: roteiro de estudos e guia de exercícios, publicado pela editora Contexto, Cristófaro Silva (2020) reconheceu o valor das teorias e recursos formais, não obstante, defendeu a necessidade de ir além, como ela fez, no início dos anos 2000, influenciada por estudiosos da área, ao romper epistemologicamente o seu percurso, até então estritamente ligado a modelos fonológicos formais, passando a orientar-se por uma visão experimental, da Fonologia do Uso e da hipótese das multirrepresentacionalidades.

Cinco premissas foram apresentadas por Cristófaro Silva como estruturantes de sua fala. A primeira é a de que a ciência é patrimônio da sociedade, isto é, os pesquisadores contribuem ativamente para a construção de um patrimônio científico compartilhado socialmente. A segunda relaciona ciência e desigualdade social, porquanto, para ela, a ciência deve ter como objetivo minimizar os efeitos da desigualdade social. Por sua vez, a terceira premissa é a de que, no campo científico, coexistem diversas propostas, a quais devem ser marcadas pela capacidade de escutar e de exercitar a tolerância. A quarta premissa concebe o conhecimento como um processo gradual e dinâmico. Por fim, a apresentar a quinta, ela lembra a permanente mutabilidade da ciência como motivação para a sua fala, que se volta para o que mudou nos estudos fonéticos e fonológicos. 


\section{REVISTA DA ABRALIN}

Na sequência, a estudiosa lembrou que a divisão da Linguística em áreas específicas tem apenas caráter metodológico, pois, em suas palavras, a gramática opera em sua totalidade, e não em níveis isolados. Adiante, chamou a atenção para os avanços da Fonética e, para tanto, fez referência a produções bibliográficas representativas desse processo e apresentou temas - audição, percepção da fala, desenho experimental etc. - que a referida área passou a abarcar. Nesse ínterim, ela abordou a necessidade do diálogo entre a Fonética e as diversas áreas de conhecimento.

Ao introduzir suas considerações sobre a Fonologia, a linguista refletiu sobre o papel do Alfabeto Fonético Internacional (IPA), de maneira a destacar a sua relevância para os estudos nas áreas em pauta, considerando, entretanto, a sua natureza simbólica, a sua inspiração no sistema alfabético e o fato de ele não dar conta da complexidade de toda a representação das línguas naturais. Com o intuito de evidenciar os problemas desse sistema, a palestrante recorreu às divergências nas representações dos glides no Português Brasileiro $(\mathrm{PB})$ e às ocorrências do tap ou flap $[\mathrm{r}, \mathrm{r}]$ em inglês, representados, na maioria das vezes, por um símbolo não previsto no IPA [ $\mathrm{t}$ ]. Outra problemática, segundo ela, é o uso falho de colchetes e barras transversais para distinção do que é fonético ou fonológico, respectivamente. Para ilustrar algumas consequências desse problema, Cristófaro Silva apresentou, brevemente, os resultados de uma pesquisa que realizou em oito livros didáticos, cujos dados mostraram a presença, nas obras, de vários equívocos nas representações fonéticas e fonológicas. Tal confusão nas representações, segundo a pesquisadora, é motivada pela grande proximidade entre a Fonética e a Fonologia. Nesse ínterim, ela lembrou que a gramática é complexa, dinâmica, sistemática e, consequentemente, abstrata - daí decorrem as abstrações fonológicas. Porém, a tais características, somase a variabilidade, que inviabiliza o alcance de uma unicidade representacional.

Posteriormente, Cristófaro Silva abordou três processos fonológicos do PB que, segundo ela, são observáveis em diferentes épocas: a nasalização de vogais, a palatalização das oclusivas alveolares e o apagamento do [i] átono. Ao abordar o primeiro processo, ela reafirmou a tese do contraste fonêmico e apresentou dados segundo os quais, no PB, estão surgindo dados emergentes, como consoantes nasais em posição final de sílaba, como nos casos de vamos / [vım] e dona Maria / [donmariə], no dialeto mineiro. O segundo processo, a palatalização, implementa-se, segundo Cristófaro Silva, de forma gradiente, ainda está em curso, dá-se em diferentes contextos e apresenta dados emergentes, segundo os quais podem ocorrer africadas seguidas de vogais diferentes de [i] como em adjunto/ [a'dzútu ] e teatro/ ['tatro ]. O último processo fonológico abordado é o apagamento de [i] átono, como nos casos: ['mezs ], [ leks ], [ s'tadu ]. Cristófaro Silva evidenciou que esse fenômeno apresenta implementação gradual, é muito relevante por interferir diretamente nos padrões acentuais e na criação de padrões silábicos inovadores, como por exemplo em participação / [ pahtjisipa'sãơ ] [ pahtspa'sãơ ].

A fonóloga destacou, então, as principais conquistas da fonologia, que são: a existência de um rico aparato formal para a explicação e descrição do componente fonológico, a documentação vasta e diversa da evolução dos fenômenos fonológicos e a formulação da hipótese da multirrepresentacionalidade.

Na sequência, a fonóloga afirmou que, ainda que, para modelos formais, as representações fonológicas $(\mathrm{RF})$ excluam informações redundantes, pesquisas que lidam com o contraste fonêmico 


\section{REVISTA DA ABRALIN}

fino mostram que não se deve descartar o detalhe fonético nas representações. Além disso, defendeu que as RF podem ser alteradas, ao destacar que as mudanças sonoras, em curso ou consolidadas, têm um impacto permanente nas representações abstratas.

Ao abordar o papel da variabilidade na organização fonológica, a pesquisadora afirmou que não é apenas o contexto fonológico que deve ser considerado, sendo necessário considerar outras informações relevantes relativas ao nosso conhecimento fonológico e linguístico, como a nossa capacidade de reconhecer palavras e diferentes vozes. Por fim, a pesquisadora advogou a favor de modelos multirrepresentacionais e afirmou que lócus da representação, na perspectiva da teoria de exemplares, são palavras, são construções que fazem parte da nossa organização gramatical.

Para concluir, a linguista disse que o maior desafio está em formalizar uma proposta integrativa, multi e transdisciplinar, como componente das Ciências Cognitivas. Apontou, ainda, que os avanços científicos são lentos, mas que é necessário elaborar novas terminologias. Por fim, evidenciou que temos um longo caminho rumo ao conhecimento do PB e das línguas minoritárias e, sobretudo, reforçou a necessidade de socializar todo esse conhecimento, visto que a ciência tem grande responsabilidade social na promoção de intelectualidade social.

\section{REFERÊNCIAS}

FONOLOGIA: conquistas e desafios. Conferência apresentada por Thaïs Cristófaro Silva [S. l.: s. n.], 2020. 1 vídeo (1h 47min 45s). Publicado pelo canal da Associação Brasileira de Linguística. Disponível em: https://www.youtube.com/watch?v=4V6soidUjOw\&t=4665s. Acesso: 16 jul. 2020. 